\title{
SEISMIC RISK AND DESIGN CRITERIA
}

\author{
A.V. Hatrick*
}

\section{ABSTRACT}

By making use of published data on the risks of earthquake occurrence in New Zealand, and on the risks of structural failure in the event of an earthquake occurring, a method is developed for estimating the risks of structural failure due to earthquakes. These risks are compared with the provisions of the New Zealand national building code, and with other risks which are accepted in daily life. Their use in economic decision making is illustrated.

\section{LIST OF SYMBOLS AND FORMULAE}

$$
\begin{aligned}
& A=\text { peak ground acceleration - ( }(\% \mathrm{~g}) \\
& I=\text { intensity on Modified Mercalli } \\
& \text { (MM) scale } \\
& \mathrm{N} \text { = normalised intensity of earthquake } \\
& \text { A for earthquake event } \\
& =\overline{\text { A for design earthquake }} \\
& P=\text { probability of "failure" - (\%) } \\
& Q=\text { probability of earthquake event - } \\
& Q_{i}=\text { probability of earthquake event } \\
& \text { of intensity } i \\
& =\frac{1}{T_{i}}-\frac{1}{T_{i+1}} \\
& T=\text { return period of earthquake event - }
\end{aligned}
$$

\section{INTRODUCTION}

In recent years the concept of risk in relation to human affairs has become more familiar to members of the public. Such a statement as "there is no such thing as absolute safety, there are only different degrees of risk" is now almost respectable, whereas not so long ago it would have been considered an attempt to hide some unsafe practice in the obscurity of technical jargon. At the same time engineers are more willing to discuss risks of structural failure in quantitative terms, and are paying more attention to such concepts as the statistical variability of structural loads and of the load-bearing capacities of structures.

* Chief Development Engineer, Power Division, Ministry of Works and Development, Wellinqton, New Zealand.
Structural codes for earthquake-resistant design have to deal with loading conditions which are random in occurrence, vary widely in maanitude, and have an upper limit so large that it is usually considered impracticable to design to meet it. These conditions are prime candidates for treatment in terms of risk assessment, but so far compilers of codes have avoided explicit statements about the levels of risk associated with their codes' requirements.

Much research, development and writing on these topics emanates from the field. of nuclear power, where the explicit recognition of risk has been long and widely discussed. One well known study, released in 1975, is the USNRC "Reactor Safety Studv" often referred to as the Rasmussen Report (1). It deals with the risk of a coremelt accident occurring at a nuclear reactor sited in the eastern United States, arising from a wide spectrum of causes, includina earthquakes. The report has been subjected to searching scrutiny by proponents and opponents of nuclear power, and has been criticised in some respects, but so far as is known no criticism has been levelled at the methodologv of its earthquake risk assessment (although the data-base has been challenged as inadequate).

The present paper uses similar methods to make some estimates of the risks of structural failures in New Zealand due to earthquakes, and attempts to relate them to the provisions of the national building code, and to other risks which are accepted by society. They are also considered in relation to the economic judgements which must be made when deciding on design criteria.

The concept which will be used is that the probability of a structure failing due to an earthquake is the product of two other probabilities; one being the probability that the structure will fail. given that the earthquake occurs. The combined probabilities have to be summed over the whole range of possible earthquakes which could cause failure.

\section{THE RISK OF AN EARTHQUAKE OCCURRING}

In some countries attempts are made 
to access the risk of earthquakes at particular sites bv mechanistic methods which involve identifying potential sources of earthquakes (often described as "causative faults"), and predicting the probable energy-release and the attenuation of the seismic waves as they travel from the source to the site in question.

These methods are not suited to seismological conditions in New Zealand, where it is often impossible to relate the sources of earthquakes to known geoloqical features. An alternative approach has been adopted by W.D. Smith (2) using the historic record of earthquake occurrences and the observed characteristics of isoseismal patterns. Smith has published mass giving estimated return periods of various Modified Mercalli (MM) intensities for all parts of the country. An example is shown in Figure 1.

Figure 2 is derived from Smith's work, and shows the return periods (for sites on averace ground) of MM intensities from VI to XII for three New Zealand localities, Wellington, Tauranga and Whangarei, which have been selected as reasonably typical of the three zones $A, B$ and $C$ recoanised in the national building code (3). It must be pointed out that Smith's estimates do not extend to intensities above IX, and those used for the higher intensities in this paper have been obtained by extrapolation from his data. Smith also warns that extrapolation may be unreliable for return periods greater than the period of historic record. For the present exercise we have no alternative to such extrapolation, but the possible errors should be borne in mind.

Figure 2 relates the various intensities to their return periods or recurrence rates. For our purposes we need to express them in terms of probability, which is done by using the property that an event which has a return period of $T$ years has a probability of occurrence of $\frac{1}{\mathrm{~T}}$ per year.

The return periods plotted against each intensity in Figure 2 are for that intensity or greater, and thus the corresponding probabilities are also for that intensity or greater. The probability of earthquakes of any particular intensity is therefore the difference between the probability of that intensity or greater, and the probability of the next higher intensity or greater. Thus the probability of MM VIII is equal to the probability of "MM VIII or greater" minus the probability of "MM IX or greater".

\section{RELATIONSHIP BETWEEN INTENSITY AND SEISMIC} FORCES

It is well known that intensities are essentially measures of damage, and when attempts are made to correlate them with numerical values representing seismic forces it is found that each intensity covers a band of such values. Many correlations have been published, and that used here, presented in Figure 3, has been derived from publications by N.M. Newmark (4) (5). It follows the commonly used practice of representing the earthquake forces by peak ground accelerations.
It is of course well known that the seismic forces arising from any particular earthquake cannot adequately be described only by thepeak ground acceleration, or by any other single-valued parameter. However, the usage can be justified provided it is made clear how it is to be interpreted.

E. Rosenblueth has classified earthquake motions into four types (6). His Types 1 and 3 are respectively a signle sharp shock essentially unmodified by multiple wave reflections in the ground, and a long ground motion with pronounced periodicity strongly modified by the local ground response. Type 4 involves large-scale permanent ground demormation. Here we are concerned with his Type 2 (exemplified by the El Centro 1940 record) which is the type most commonly adopted for design spectra for building codes. It is a "white noise" type associated with moderate distances from the focus, and occurring on firm ground. According to Rosenblueth the firm-ground records of almost all major earthquakes originating along the Circumpacific Belt are of this type, which makes it especially suitable for the present study.

The smoothed response spectra of Type 2 earthquakes, when plotted in tripartite form, have a family resemblance, although they differ quantitatively, depending on the intensity of the shaking (7). In these terms then, we can consider the peak ground acceleration as a scaling factor for the corresponding smoothed response spectrum. To put it another way, it is the zero-period acceleration of a smoothed response spectrum, appropriate to firm ground, due to an earthquake of moderate to large magnitude, occurring within a moderate distance, and having a substantial duration.

From here on we shall describe each intensity in terms of peak ground acceleration, using the geometric mean value for the band of accelerations covered by the intensity value. For example, Figure 3 shows MM VIII extending from $0.12 \mathrm{~g}$ to $0.23 \mathrm{~g}$, which we shall typify by its mean of $0.17 \mathrm{~g}$.

\section{THE RISK OF STRUCTURAL FAILURE IN AN} EARTHQUAKE

Once limit-state design seismic forces have been specified the structural designer will seek to proportion his structure so that (according to his calculations) some major items will just reach their limiting strength or deformation at the specified loading. In practice each of the elements entering the calculations (whether they be loads, quality of construction, properties of materials, or methods of calculation) is subject to some uncertainty and scatter in the data used.

An assessment of the risk of failure should take into account this variability or uncertainty in all the elements. In the present state of knowledge any such attempt must be a very "broad brush" one, but nevertheless it has been thought worth trying. One approach, which has been developed by N.M. Newmark (4), (5), is used in the Rasmussen Report (1). 

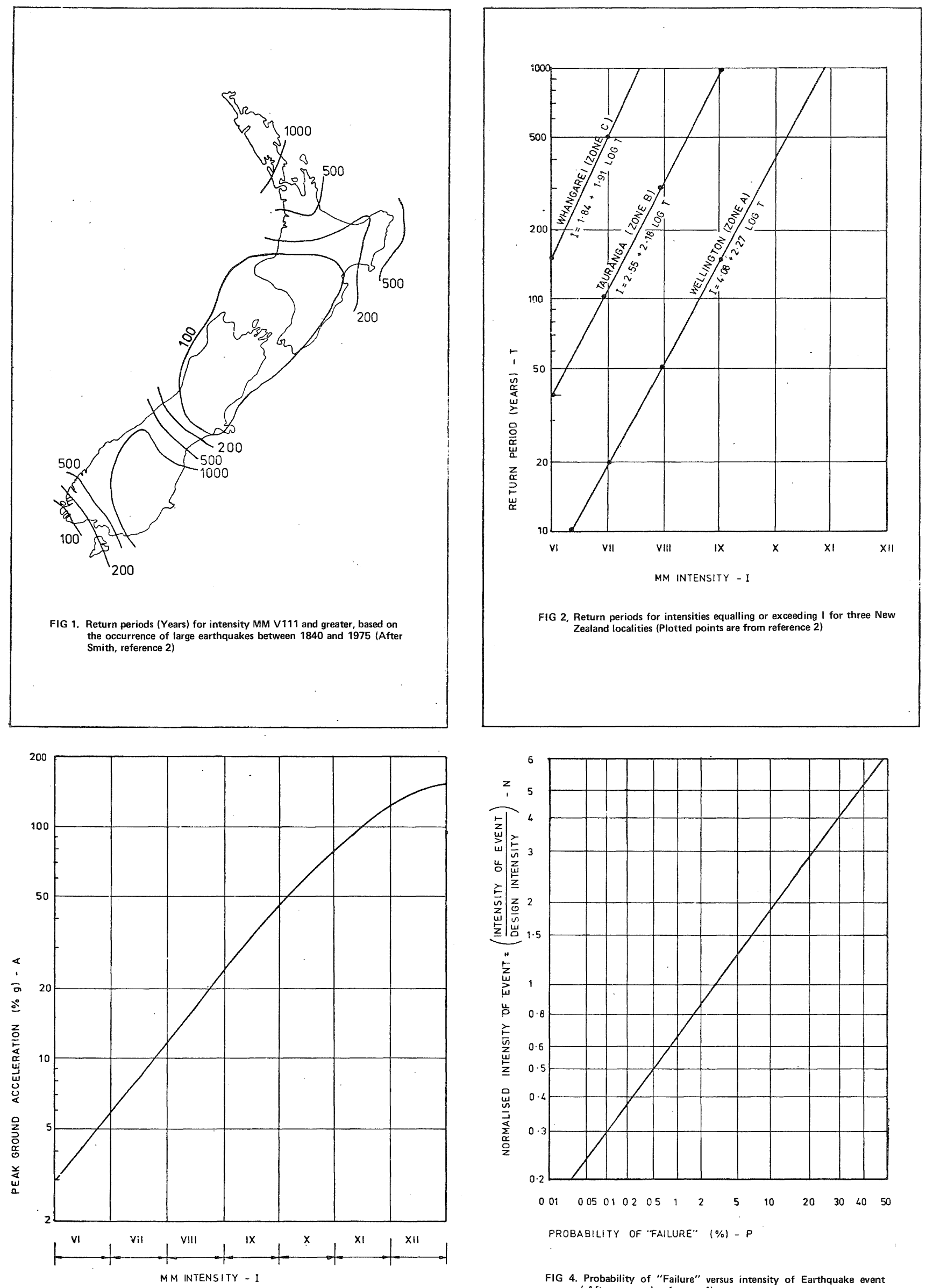
FIG 4. Probability of "Failure" versus intensity of Earthquake event
(After newmark reference 4) 
Newmark takes into account the probabilities of the earthquake forces being greater or less than those corresponding to the nominal intensity. He also considers the probabilities that the values of structural response, damping, ductility, and structural capacity may be greater or less than the values assumed for design. By combining all these probabilities he arrives at the probability that a structure will fail, in the event that it experiences an earthquake of that intensity for which it was designed to reach its limit state. For structures designed to ordinary building codes, and constructed to ordinary reasonable standards, he concludes that the risk of "failure" in such a design earthquake is about $3 \%$.

It must be understood that "failure" does not mean total collapse. It means that some important parts of the structure have been badly deformed and damaged, and the structure may even be beyond economic repair. There is ample evidence from past earthquakes that structures can and do reach such a condition, but still survive to the extent that their occupants have an excellent chance of avoiding serious or fatal injury.

However, structures are not only at risk of attack by earthquakes equal to those they are designed for. We must also consider the risk of failure due to more severe earthquakes, and recognise that there is some small but finite risk of failure in earthquakes less severe than the design earthquake. (This arises from the possibility that the variability of materials, quality of design and construction, and structural response will all trend in the adverse direction simultaneously.) By such considerations Newmark arrives at estimates of the probability of failure which are presented here (in slightly modified form) as Figure 4.

Figure 4 uses a "normalised intensity", defined as the intensity of the earthquake event divided by the design intensity. Both intensities are in terms of the mean value of the peak ground acceleration for that intensity (from Figure 3). For the design earthquake the normalised intensity is 1 and the probability of failure about $3 \%$. For an earthquake of one half the design intensity (about one MM intensity point lower) the normalised intensity is 0.5 and the probability of failure about $0.5 \%$. For avery severe earthquake, with a normalised intensity of 3 or more, the probability of failure is $20 \%$ or greater,

\section{THE TOTAL SEISMIC RISK}

We now have stimates for the risk of occurrence of earthquake events of all intensities at any specified locality, and for the risk of "failure" in each event. By combining the two we can arrive at the risk of earthquake-generated "failure" of an engineered structure designed for any specified intensity. An example of the calculations is given in Table 1 , and the full results are presented in
Figure 5. We see from Figure 5 that, for example, a structure in Wellington designed to reach its limit state in an earthquake of MM intensity IX has a risk of "failure" of $6 \times 10^{-4}$ per year.

\section{INTENSITIES OF DESIGN EARTHQUAKES}

The New Zealand national building code does not explain what intensities are intended to be associated with the seismic design co-efficients specified in NZS 4203 (3). However, it has been stated (8), (9) that the design spectra used in it are similar to those in an earlier code NZS 1900, Chapter 8 (10). A commentary on the latter code (II) states that the seismic coefficients specified in it for public buildings (on firm ground) are deemed to be adequate for intensities $M M 9,8 \frac{1}{2}$ and 8 in the three zones A, B and C, while those for other (non-public) buildings are about half a step lower. We can therefore infer that the new code is intended to be adequate for the same intensities (see Appendix).

In Figure 5 these intensity ranges correspond to risks of failure per year of about 6 to $9 \times 10^{-4}$ in Zone $\mathrm{A}$, somewhat lower at 2 to $4 \times 10^{-4}$ in zone $B$, and substantially lower in zone $C$ at 6 to 8 $x 10^{-5}$. Although logically one would expect the code to aim for a uniform level of risk in all three zones the greater conservatism in Zone $\mathrm{C}$ design earthquakes possibly arises from the lesser amount of statistical data from that zone.

For all three zones the curves in Figure 5 have a characteristic shape. At the low-intensity end they tend to become horizontal at finite values of the design intensity, suggesting that unless some minimum provision is made against earthquakes, failure is probable within a time comparable with the life of the building. The minimum design intensities thus indicated are surprisingly high for Zones A and B - MM VIII and MM VII respectively.

At the other end of the scale all three curves tend to become vertical, suggesting that beyond a certain stage not much will be gained in terms of reduced risk by pushing design intensities higher and higher.

In Zones $\mathrm{B}$ and $\mathrm{C}$ the design intensities specified in NZS 4203 result in very low risks of failure, with return periods of several thousand years. For even lower levels of risk the curves start to climb steeply, indicating that to achieve any significant reduction in risk would require a very large investment in increased structural capacity.

In zone $A$ the issue is not so clearcut, and the question may be asked whether the cost of raising the code design intensity from MM IX to MM $X$ would be worthwhile in terms of reduced human or financial risk. Possible answers are considered in the following sections. 


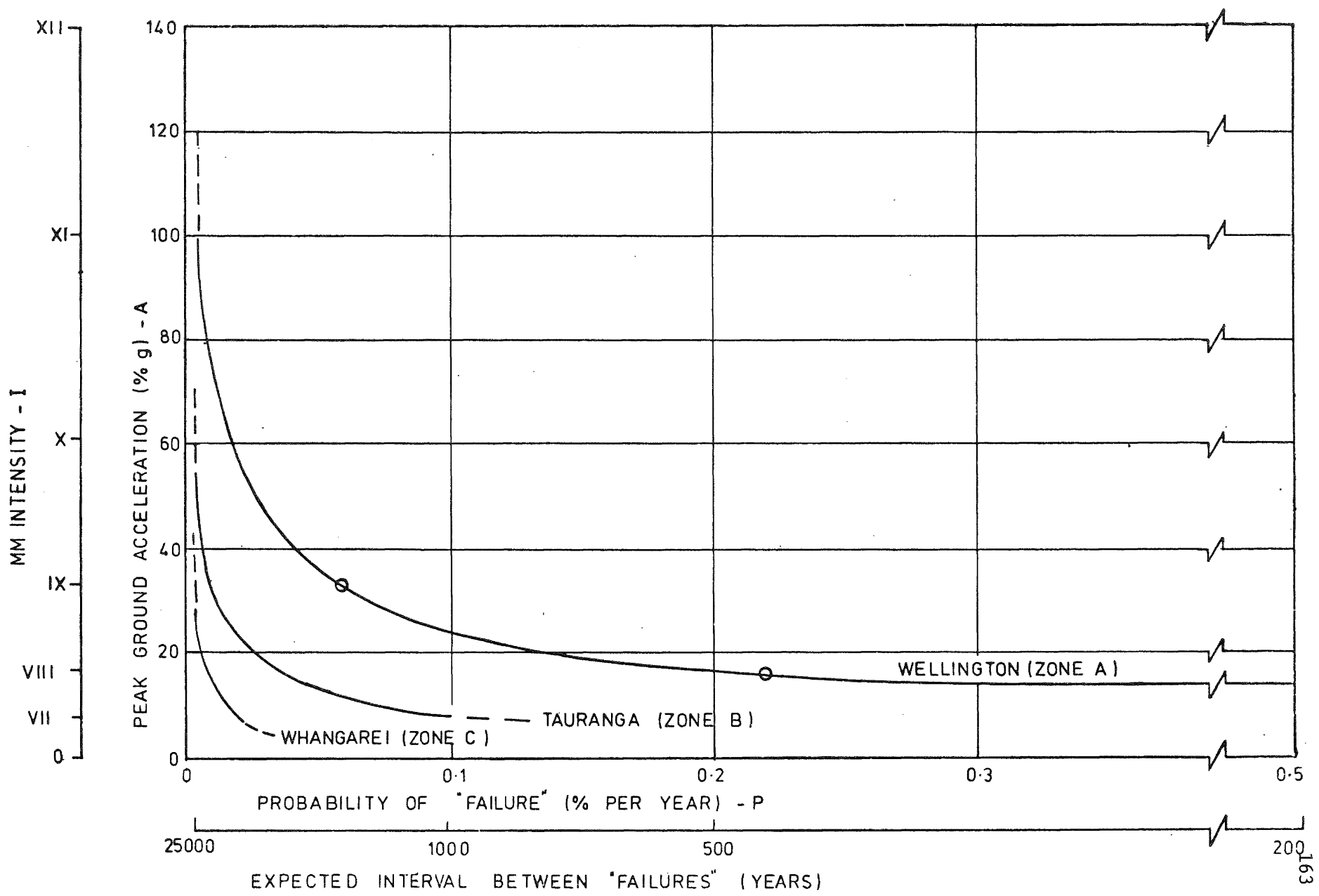

FIG. 5: RISK OF FAILURE VERSUS INTENSITY OF DESIGN EARTHOUAKE

\begin{tabular}{|c|c|c|c|c|c|c|c|c|}
\hline \multirow{2}{*}{\multicolumn{3}{|c|}{$\begin{array}{c}\text { EARTHQUAKE } \\
\text { EVENT }\end{array}$}} & \multicolumn{6}{|c|}{ DESIGN EARTHQUAKE } \\
\hline & & & \multicolumn{3}{|c|}{ MM VIII } & \multicolumn{3}{|c|}{ MM IX } \\
\hline I & A & Q & $\mathrm{N}$ & $\mathrm{P}$ & $p \times 2$ & $\mathrm{~N}$ & $P$ & $P \times 2$ \\
\hline VI. & 4 & $91 \times 10^{-3}$ & 0.25 & 0.001 & $0.09 \times 10^{-3}$ & 0.13 & 0 & $0 \times 10^{-3}$ \\
\hline VII & 8 & 33 & 0.5 & 0.005 & 0.17 & 0.25 & 0.001 & 0.03 \\
\hline VIII & 17 & 12 & 1 & 0.03 & 0.35 & 0.5 & 0.005 & 0.06 \\
\hline IX & 33 & 4.3 & 2 & 0.12 & 0.52 & 1 & 0.03 & 0.13 \\
\hline $\mathrm{x}$ & 61 & 1.6 & 3.7 & 0.28 & 0.45 & 1.8 & 0.10 & 0.16 \\
\hline$X I$ & 100 & 0.57 & 6 & 0.5 & 0.29 & 3 & 0.20 & 0.11 \\
\hline$X I I$ & 140 & 0.32 & 8.4 & 1 & 0.32 & 4.2 & 0.32 & 0.10 \\
\hline & & & & $\Sigma=$ & $2.20 \times 10^{-3}$ & & $\Sigma=$ & $0.59 \times 10^{-3}$ \\
\hline
\end{tabular}

NOTES: $1 . \quad Q$ is derived from Figure 2 and the formula $Q_{i}=\frac{1}{T_{i}}-\frac{1}{T_{i}}+1$ $P$ is lerived from Figure 4.

2. Results are shown as ringed points on Figure 5 


\section{EARTHQUAKES AND PERSONAL RISK}

It is of interest to see how the risks to people from earthquakes compare with other personal risks to which we are all exposed. The matter is complicated by the fact that most people spend different parts of their lives in different seismic risk situations, so we will confine our attention to that part of the population who spend a significant proportion of the year in (non-public) buildings designed in accordance with the national building code. We have seen that for such buildings in zone $A$ the code is intended to be adequate for intensities of about MM $8 \frac{1}{2}$, no doubt with some extensive damage, perhaps even extending to "failure" (in the limited terms explained above), if the earthquake forces are in the higher part of the intensity range.

From Figure 5 we see that the risk of such "failure" is about $10^{-3}$ per year. We have also seen that such a "failure" is not necessarily catastrophic (unless perhaps it is due to a very severe earthquake, say two or more points higher than the design intensity). In the absence of statistical data a reasonable estimate of the risk of death or severe injury to an individual in such a "failed" building might be between 1 chance in 10 and 1 chance in 100. Thus the risk of his being killed or severely injured by an earthquake while in the building is between $10^{-4}$ and $10^{-5}$ per year. This is comparable with his risk of death from drowning or accidental poisoning, and substantially less than his risk of being killed in a traffic accident - about $2 \times 10^{-4}$ to $3 \times 10^{-4}$ per year (12). We may conclude that as far as earthquake risk is concerned the building code is giving the average citizen a fair deal.

\section{EARTHQUAKE RISKS AND ECONOMIC DECISIONS}

In the economic context complications arise because of the differing economic criteria used by different individuals or organisations. For example, an insurance company is less concerned with the risks to individual buildings than with ensuring that its annual premium income is not out-weighed by its annual payout on losses. Its greatest threat is the occurrence of a single catastrophic event which involves it in very great payouts at one time and for this reason it will seek a wide spread of the risk it underwrites. In New Zealand, nost earthquake insurance is taken out of the hands of insurance companies and borne, in effect, by the State.

One example which can be studied is that of a major organisation such as an electric power company, which carries its own insurance. It must be emphasised that what follows is only a hypothetical exercise, and bears no relationship to the operations of the New Zealand Ministry of Energy.

Let us assume that the company owns 10 power stations, each costing $\$ 360$ million, with an output of $3000 \mathrm{GWh}$ per year each. As they become obsolescent they are replaced on a continuing programme at a rate of 1 every 3 years, involving an annual expenditure of $\$ 120$ million.

It is assumed that the stations are in a seismic area, but sufficiently well spread that any one earthquake event would only seriously affect one station. The loss of a station would involve the cost of replacing it, plus the cost of replacing its lost energy production, from some more expensive source. Let us assume that the marginal cost of replacing the lost energy is $\$ 0.01$ per $\mathrm{KWh}$, and that this costpenalty last for 6 years, until the replacement station is built. Then the total lost energy is 18,000 GWh, with a marginal cost of $\$ 180$ million. To this is added \$360 million for replacing the station, making a total potential loss of $\$ 540$ million.

The question now arises whether to increase the seismic resistance of the new stations, which would increase their cost by $5 \%$, but would reduce the risk of loss in an earthquake from $6 \times 10^{-4}$ per year to $2 \times 10^{-4}$ per year. (Compare the change in risk for Wellington in Figure 5 by raising the design earthquake from MM IX to MM $\mathrm{X}$ ).

The annual cost of such a change would be 5 \% of the annual expenditure on building new stations, that is $5 \%$ of $\$ 120$ million, or $\$ 6$ million.

The annual benefit would be the reduction in risk of the loss of a station. The reduction is from $6 \times 10^{-4}$ per year to $2 \times 10^{-4}$ per year, that is $4 \times 10^{-}$ per year, and this applies to each of the 10 stations. Thus the total value of the benefit is $\$ 540$ million $\times 10 \times 4 \times 10^{-4}$ per year, that is $\$ 2.16$ million per year. To gain such a benefit would cost $\$ 6$ million per year - evidently not a good bargain.

The economic analysis is of course grossly over-simplified. In particular it only considers the consequences of "failure", whereas a full treatment would consider the consequences of different degrees of damage (see, for example, references 13, 14 and 15). Nevertheless it does consider a case where the economic consequences of major damage are more severe than normal, and even so does not disclose any justification for designing for seismic resistance beyond NZS 4203 .

It may be reasonable to infer that in normal situations the level of seismic resistance aimed at by NZS 4203 will provide adequate protection for the financial investment. At the very least the analysis suggests that any proposals to design for seismic resistance beyond that provided by NZS 4203 should not be accepted until they have been closely scrutinised for their cost-effectiveness.

\section{DISCUSSION}

Any conclusions we draw must be tempered by recognition that they cannot be any better than the basic data on 
which they rely. This basic data is shown in Figures 2, 3 and 4 , and it is worthwhile to examine its validity.

As has been pointed out, Figure 2 has been produced by extrapolation of the data in reference (2) to return periods much greater than the historic record. It is known that earthquake records in countries with a long history, such as China, show periods of activity and quiescence which may be centuries in duration, and therefor longterm estimates in New Zealand based on only a century or so of observation may be unreliable. Smith (2) has suggested that extrapolation to the longer return periods may be possible by making use of geological considerations. As the present paper shows, extrapolation to very long timeperiods is not required. An indication from the geological profession as to whether the seismicity in the next four or five hundred years is likely to be more or less intense then, or much the same as, the last 140 years would be of great value.

Figure 3 illustrates the essential requirement of a means of translating values of intensity into terms which can be used in engineering calculations. It is generally recognised that no satisfactory solution to this problem has yet been found. However there are indications in recent literature that more satisfactory approximations than those we have at present may be on the way. It is worth noting that for the methods used in the present paper it is not essential to correlate intensity with any single physical parameter such as acceleration, although that has been done here for convenience. What is required is a method of expressing an intensity rating in terms of seismic loads on a structure. In any particular case, and for design purposes, this could be done by the use of suitable families of response spectra, or suites of timehistories.

The derivation of Figure 4 is described by Newmark (4) as "somewhat heuristic". This is inevitable in our present state of knowledge, but at least it represents the best judgement of an acknowledged and experienced expert. Recent literature shows that much interest is being taken in the general problem of risk in relation to structural damage and failure (reference 13,14 and 15 are examples), and further development seems likely in the near future.

\section{CONCLUSIONS}

1. By making use of published data on the risks of earthquake occurrence in New zealand, and on the risk of structural failure in the event of an earthquake occurring, a method has been developed for estimating the risk of failure caused by an earthquake to a structure anywhere in New Zealand.

2. Such estimates of seismic risk have been presented for three localities in New Zealand, representative of the three seismic risk zones in the national building code.

3. It is concluded that the level of earthquake resistance aimed at by the code is to meet risks of structural failure of the order of 6 to $9 \times 10^{-4}$ per year in Zone $A$, somewhat lower in Zone $B$ and substatially lower in Zone C. (Failure here means that important structural elements are loaded beyond their limitstate strength or deformation. It does not necessarily involve total collapse.)

4. Comparison with other risks suggests that the level of seismic resistance aimed at by the code results in a risk to the individual of death or serious injury from earthquakes which is comparable with, or lower than many other risks which people accept in their daily lives.

5. The level of seismic resistance aimed at by the current $\mathrm{NZ}$ building code is probably adequate as a protection for financial investment in most instances.

\section{ACKNOWLEDGEMENT}

I wish to express my thanks to the Commissioner of Works and the Chief Power Engineer, Ministry of Works and Development, for permission to publish this paper.

\section{APPENDIX}

\section{REPRESENTATION OF INTENSITY}

The Modified Mercalli scale of seismic intensity, as used by seismologists. is a scale in discrete steps and there is no concept of fractional values. It is expressed in Roman numerals. It is used in this way in most of the present paper, with the assumption that each intensity step represents a band of values of seismic forces.

However the sections derived from the Commentary on NZSS 1900, Chapter 8 (11) follow the usage adopted therein of expressing intensities in Arabic numerals, and permitting fractional values. Although no precise definitions are given the usage is assumed to indicate, in a general way, positions on the curve of Figure 3 .

Smith (2) has introduced, for calculation purposes, what he terms a continuous intensity which he defines as follows:

"The continuous intensity (Arabic numerals) is defined to take integral values equal to the Modified Mercalli intensity (Roman numerals) at the isoseismals enclosing observations of that intensity, with a continuous variation in between."

This definition thus provides for arabic numerals and fractional values of intensity, in a manner similar to that used in reference (II), and so permits a reasonably precise meaning to be attached 
to the usage.

\section{REFERENCES}

(1) Reactor Safety Study - WASH 1400, US Nuclear Regulatory Commission, Washington, 1975.

(2) Smith, W.D., Statistical Estimates of the Likelihood of Earthquake Shaking Throughout New Zealand, Bull. NZ Nat. Soc. for Earthquake Engineering, Vol 9, No 4, Dec. 1976.

(3) NZS 4203:1976, Code of Practice for General Structural Design and Design Loadings for Buildings, Standards Association of New Zealand, Wellington, 1976.

(4) Newmark, N.M., Overview of Seismic Design Margins, Program Report, Reactor Licensing and Safety, Vo. 2, No 1, pp 63-84, Atomic Industrial Forum, May 1975 .

(5) Newmark, N.M., Probability of Predicted Seismic Damage in Relation to Nuclear Reactor Facility Design, US Nuclear Regulatory Commission, September 1975.

(6) Rosenblueth, Emilio, On Earthquake Resistant Design, N.Z. Engineering Vo. 21, No 9, pp 371-386, September 1966.

(7) Newmark, N.M. and Hall, W.J., Seismic Design Criteria for Nuclear Reactor Facilities, Proc 4 WCEE, Santiago, Chile, 1969.

(8) Glogau, O.A., The Objective of the NZ Seismic Design Code, Bull NZ Nat. Soc. for Earthquake Engineering, Vol 5. No 4, December 1972.

(9) Kolston, D. Notes on the New Zealand Earthquake Loading Provisions, BuIl NZ Nat. Soc. for Earthquake Engineering, Vol 8 , No 2 June 1975 .

(10) NZSS 1900, Chapter 8, NZ Standard Model Building Bylaw, Basic Design Loads, NZSI (now Standards Assn of NZ), 1965 .

(11) MP 12, Commentary on Chapter 8 of NZSS 1900, NZSI (now Standards Assn of NZ), 1965 .

(12) New Zealand Official Yearbook 1977, Department of Statistics, Wellington.

(13) Whitman, R.V., Biggs, J.M., Brennan, J.E., Cornell, C.A., de Neufville, R.L., and Vanmarcke, E.H., Seismic Design Decision Analysis, Journal of the Structural Division, ASCE, Vol 101 , No ST5, May 1975.

(14) Stevenson, J.D., The Economic Effect of Increased Seismic Load on Nuclear Power plant Design and Construction Costs, Nuclear Engineering and Design 48 (1978) 231-243.
(15) Elms, D.G. and Silvester, D. Cost Effectiveness of Code Base Shear Requirements for Reinforced Concrete Frame structures, Bull NZ Nat. Soc. for Earthquake Engineering, Vol 11 , No 2, June 1978 .

A slightly shorter version of this paper was presented at the South Pacific Conference on Earthquake Engineering, Wellington May 1979. 